\title{
Irony and Communicative Values in Political Discourse: Intercultural and Interpersonal Communication
}

\author{
Anna Gornostaeva \\ Moscow State Linguistic University, Russian Federation
}

\begin{abstract}
In the time of globalization and developing intercultural communication it is necessary not only to master a foreign language but to acquire cultural and communicative skills. Recently the item of developing intercultural competence has acquired a particular importance. It is recognized that successful intercultural communication is impossible without the knowledge of background information, which includes communicative and cultural values, history and traditions. Being an essential part of a language culture, humour and irony pose vast challenges for research. This article concentrates on irony, as a communicative value of certain cultures. It is noted that irony is an integral part of the English communicative culture [1] and understanding irony and humour in a foreign language ensures a fruitful dialogue between cultures [2]. This phenomenon has national and cultural peculiarities, which should be taken into consideration while understanding and interpreting the implied sense. On the contrary, the inability to penetrate into the disguised meaning of an ironic utterance may cause communicative failures, misunderstanding and even conflicts. The aim of the study is to determine the links between cultural and communicative values and mechanisms of irony in the British and American culture and to find common and different trends in irony usage. The hypothesis is: irony is a reflection of culture and forms the picture of the world of an individual, belonging to a certain culture, and of a nation as a whole; irony is used to express and strengthen the national identity. The knowledge of ironic mechanisms is important to promote understanding between different cultures. In discourse (in political discourse, in particular) irony performs different functions - from mockery and attack to self-defense and discharging tension. The appropriate ironic mechanism and the ironic mask, chosen by the speaker, corresponds to his/her communicative intention and contributes to creating a better effect on the interlocutor and the audience. The material, used for the analysis, is represented by the recent speeches of British and American political and cultural figures. The results of the study can be applied in the development of discourse theory as well as teaching and learning intercultural communication.
\end{abstract}

\section{Introduction}

In the modern globalized world connections between nations are becoming stronger and questions of intercultural communication require primary attention. It has become obvious that mastering a foreign language is not sufficient to ensure successful dialogue and understanding, but it is also important to have enough knowledge of cultural and communicative values, which form an integral part of the picture of the world, present in people's mind. These values are reflected in the language, its vocabulary and phraseology and find manifestation in the way expressive means and stylistic devices are used in discourse. This article focuses on political discourse for a number of reasons.

1. Recently the attention of researchers has been attracted to political communication, as a bright example of intercultural and interpersonal discourse, its mechanisms and language means. These phenomena are analyzed from different angles and through various approaches, including political, cultural and linguistic ones. So, the interest to political discourse is high.

2. Contemporary political discourse reflects the current situation in society and shows the recent changes in people's taste and desires.

3. Political and cultural figures demonstrate examples of speech, which has an appeal not only to the interlocutor, but to a third party the audience, for the sake of who everything is said and done. That is why political discourse is usually bright, expressive and convincing.

The central figures in political communication are the participants and the strategies of persuasion and manipulation. The aim of political discourse is gaining and holding power, the instrument to achieve this aim is language. One of the expressive means is irony, whose functions range from attack and mockery to self-defense and entertainment and rely on communicative context, background and the type of relations between the interlocutors. It should be noted, that irony, as a category of discourse, is a product of collaboration between the participants of 
the conversation: one part is responsible for producing irony, the other - for understanding it correctly. In the process of intercultural and interpersonal communication it is necessary to absorb and understand national irony, be able to interpret it in the right way and react appropriately. The inability to understand ironic utterances of a foreign interlocutor can cause communicative failures, lead to growing tension and eventually discourage the speakers. On the contrary, background knowledge about the partner's national humour peculiarities will contribute to better understanding and result in efficient productive communication.

The hypothesis is the following: the use and frequency of irony depends on cultural and communicative values the speakers have. The material, chosen to illustrate the idea, proves the point and poses vast challenges for further analysis.

\section{Methodology}

Political discourse is currently interpreted as a social phenomenon, while politics is associated with power and force: "Politics is the realm of the decision, of action in the social world... the category of hegemony... politics is an act of power, force and will" [3]. Consequently, the discourse of politics has the same characteristics.

According to critical discourse analysis (CDA) $[4 ; 5 ; 6 ; 7 ; 8 ; 9 ; 10 ; 11$ and others] there is mutual influence between politics and discourse: the latter can form and change the former, as well as contribute to changes in the situation in the world. Political communication is always ideological, it involves certain instruments to persuade the audience and manipulate it. Irony is regarded as one of such instruments and a feature of the English communicative style [12], which performs different functions in political discourse. It creates emotional background $[13 ; 14]$, reflects cultural and communicative values $[15 ; 16 ; 17]$ and helps the speaker to create maximum effect.

In order to compare and find common trends and differences in the national ironic discourses it is possible to single out several scenarios, such as: mockery or attack; self-defense; entertaining the interlocutor and the audience; optimizing interpersonal communication etc. In analyzing the role and functions of irony in political discourse in the frame of national mentality, I rely on the hypothesis that these notions are integral elements in the English style of communication [1]. The roles, irony performs in discourse, are variable - from mocking to soothing, as well as entertaining or making a statement. The role of self-irony is most important, as it serves to discharge tension and save the face of the speaker. Irony may also express solidarity and minimize the distance between interlocutors, as well as enhance the distance and exclude outsiders, serving as a boundary marker.

In any case, the use of irony and the function it performs in discourse reflect national, cultural and communicative values.

\section{Cultural and communicative values}

In order to understand irony it is important to take into consideration a number of social factors, such as the type of relationship between interlocutors, their gender, cultural and ethnical identity. It is also important to have a background knowledge about the norms of using humour and irony in this or that culture, to be aware of what is considered to be funny. The situation, in which irony is used, should be appropriate and correspond to the mood of the communicants and to the atmosphere. It was already mentioned, that an ironic speech act is a product of cooperation, so all the parties should contribute equally. The understanding of irony can differ not only interculturally, but within one and the same culture. Individual characteristics of a person are also important.

So, a great number of factors should be taken into consideration in order to interpret an ironic utterance. If the estimation of the situation is incorrect, the communicative act is bound to be a failure.

Communicative style that is typical of a certain culture is based on cultural and communicative values and traditions, as well as on the picture of the world, that every individual has in mind. It is reflected in verbal and non-verbal means used in the process of interaction.

The issue of communicative values is one of the crucial ones for understanding people's mentality. Being individualistic cultures (unlike Russian, collectivist culture), the British and the Americans have some common communicative values. Nevertheless, there are a number of differences, which are reflected in the language, in particular, in the peculiarities of irony usage.

Among the most important communicative values researchers single out individualism (privacy), pragmatism, competition, equality, common sense, positive thinking, tolerance etc. $[14 ; 15 ; 17 ; 18]$. The priority is held by privacy and equality [18]. American cultural values include practically the same notions, with assertiveness opening the list of priorities (which means "pursue one's own best interests without denying a partner's rights" [16, p. 402]), followed by self-confidence and confidence in future. The list of communicative values also includes competition, personal success, independence and aggression [19]. The famous American slogans - "go and get it", "just do it" - 
vividly reflect the view on the world and on the role of an individual. The Americans think as positively as the British do, and value equality as well, but they are less modest and, as opposed to the British, unlikely to diminish their personal achievements. While the British tend to use understatement speaking about personal success, the Americans would rather exaggerate it, attracting the attention of the interlocutor / audience to oneself.

Even non-verbal communication has got certain peculiarities in the two cultures: while the British prefer a polite smile, performing the social function of putting other people at their ease, the Americans are famous for a broad self-confident smile, demonstrating good teeth (hence: good dentist, wellbeing, stability and prosperity).

Linguistic means chosen in the process of communication serve a definite purpose. For the British it is saving face and preserving privacy, which is clearly seen in the strategies of negative politeness [20]. Irony is one of the means realizing this strategy. American irony is more explicit and aggressive, more straight-forward and less disguised, which will be illustrated by the examples below.

\section{Irony as a characteristics of national communicative style}

Since irony is not only a linguistic phenomenon, but a way of perceiving the world, understanding national humour and irony is crucial for fruitful intercultural communication [2]. The identification of irony and its correct interpretation ensure comfortable atmosphere and optimizes interpersonal relations between interlocutors. Irony creates emotional background and divides the listeners into target audience and victims: "irony has an evaluative edge and manages to provoke emotional responses in those who "get" it and those who don't, as well as in its targets and in what some people call its "victims" $[12$, p.2]. Despite the fact that irony is inherent for many world languages and cultures, it is a characteristic feature for but a few.

Irony in the British culture is a way of national self-identification, it is a clue to understanding cultural and historic aspect. The British rely on irony and, being devoid of the opportunity to use it (at the funeral, for example) feel helpless [1]. The same cannot be applied to the American communicative culture.

\section{The role of irony in political discourse}

The language of politics reflects the existing reality, changes together with it and contributes to its formation. Political discourse highlights the peculiarities of social and cultural development. Each turn in political life of a country gives rise to creating new language symbols, such as metaphors and other expressive means [21].

Irony, used in political discourse, makes the recipient re-consider cultural values, leads to active thinking while interpreting it. When used skillfully, irony is an efficient tool to persuade and manipulate, it disguises meanings, accentuates certain features and forms public opinion and taste. In ironic discourse it is very important to take into consideration the personalities of the author and the recipient. The type of irony is directly connected with the level of education of the speaker, his/her social status, political views. It holds true about the recipient as well: it is necessary to take into account his/her character and mood, the degree of intimacy between the interlocutors. The role of emotional and psychological factors is also important [13]. Ignoring any of the prerequisites may lead to misunderstanding and communicative failure. That is why irony is a subtle device, demanding skill and experience especially in political discourse, where misunderstanding might cause major problem.

Irony and politics have much in common. Both are manipulations (irony is the one in language, politics is manipulating public opinion). They both pursue certain aims (irony strives to convey the communicative intention of the author, i.e. to create the necessary effect, while politics is aimed at gaining and withholding power). Further, ironic and political discourse have much in common in terms of functions. The common strategy of dividing into "us" and "them" also unifies irony and politics. So, analyzing irony in political discourse poses great challenges from linguistic, cultural and social point of view.

\section{Examples and commentary}

The connection of communicative values and irony, its functions and mechanisms, can be analyzed through examples of discourse of modern politicians.

In (1) Boris Johnson, the ex-Mayor of London and Secretary of State for Foreign and Commonwealth Affairs, prevents the possible criticism:

(1) It's absolutely wonderful to be here in Manchester - one of the few great British cities I have yet to insult [22].

The politician, who is known for his brutal remarks, often comes under criticism, which he is well aware of. Johnson openly admits the fact and uses irony as a preventive measure. In this utterance the speaker puts on an ironic mask of a rude person, a misbehavior, who does not hesitate to offend others. Here Johnson follows the principle "better admit, than deny", which helps to stop the possible bitter remarks from opponents. He uses self-irony, that is so typical of the British culture. 
In the interview with David Letterman (2), a well-known showman and journalist, Johnson again relies on irony while answering the question about his chances to be Prime Minister. This is an interesting example of intercultural communication, since the interviewer is an American, and the interviewee comes from Britain. For the British, it is rather embarrassing to speak about ambitious plans, possible promotion, career etc. Unlike Americans, the British are not assertive, tend to underestimate their achievements and find boasting and showing off impermissible.

(2) Letterman. Is there a possibility of being Prime Minister?

Johnson. I think that is vanishing. I have a much better chance of being reincarnated. [23].

The situation seems funny, especially now, when Boris Johnson has become Prime Minister and is rather successful in his job. But the phrase was pronounced some years before he took over power, and it was still unclear if he will win the elections. For American culture it might sound quite natural to express belief in one's own success, while the British speaker is likely to diminish his chances and use selfirony.

The irony is based on paradox and allows the speaker to save face and avoid discussing the unpleasant and embarrassing subject.

The mockery at political opponents is ironically disguised and demands background knowledge for its interpretation. A vivid illustration of this situation is demonstrated in B. Johnson's speech (3), when he suddenly refers to his opponent.

(3) Insert joke here, as Jeremy Corbyn would say [24].

The ironic sense of this utterance will be clear only to an addressee, familiar with J. Corbyn's discourse. Bearing in mind the usual official tone of the Labour party's leader's speeches and his inability to joke, the recipient can realize the ironic hint of Boris Johnson. The implicit irony points to the absence of the sense of humour (or the reluctance to use irony and humour in his speeches), and the opponent becomes a laughing stock. The function of irony here is mockery and attack.

One of the most articulate British rhetors, David Cameron, uses irony rather skillfully, here (4) in the function of defense.

(4) If you saw me in these pictures of me on the beach this summer in Cornwall you know one thing: I've got the stomach for the fight. [25].

D. Cameron uses ironic word play using the collocation "to have stomach" in two senses: direct meaning - "being plump" and figurative meaning "having power and intention for the fight". Again, we deal with the famous British self-irony, which helps to save the face and avoid direct showing off. On the one hand, the leader points out to his own good qualities, such as being resolute, strong and determined, on the other hand he speaks about the drawbacks of his appearance. This combination of the two meanings produces a humorous effect and takes the edge off the categorical remarks.

Irony in the function of attack and mockery is often used in American political discourse to criticize the opponents. The best examples of ironic exchanges can be found in pre-election discourse, where, according to the style, the speakers have to be critical and aggressive towards one another.

(5) You know I've got to talk about Trump. He lacks experience to be president but in fairness he spent years meeting with leaders throughout the world: Miss Sweden, Miss Argentina, Miss Azerbaijan... [26].

In (5) B. Obama accentuates the background information about D. Trump, namely his organizing beauty contests and love affairs with the contestants. It is clear to the public, that the "experience" has nothing to do with politics. So, assessing Trump as a possible candidate for presidency, Obama points out his inability to become the leader of the country due to low moral standards. The irony is disguised, but quite clear to those who remember the events and scandals around Trump and his love affairs.

In his turn, D. Trump uses bitter irony speaking about $\mathrm{H}$. Clinton. He is a skillful speaker, when it comes to mocking at his rivals, and uses a lot of bitter irony to accentuate the drawbacks of the opponent.

(6) This is the first time ever, ever, that Hillary is sitting down, speaking to major corporate leaders and not getting paid for it.

(7) You'll notice Hillary's not laughing. That's because she knows the jokes and all the jokes were given to her before the dinner by Donna Brazile.

(8) It is great to be here with a thousand wonderful people or as I call it "a small intimate dinner with some friends" or as Hillary calls it "her largest crowd of the season" [27]. 
In (6), (7) and (8) irony is quite explicit: Trump accuses Clinton of corruption and lacking sense of humour. In (8) Clinton is opposed to the speaker himself, having very few people to support her, while Trump's supporters, according to his statement, are numerous. In all the utterances irony is based on ambiguity: there is some additional meaning hidden behind each statement. The speaker uses ironic metaphors (her largest crowd of the season, a small intimate dinner with some friends), ironic paradox (speaking and not getting paid for it), ambiguous irony (she knows the jokes and all the jokes were given to her before). All these various means create a certain atmosphere - mocking, teasing, attacking.

Jeb Bush, another candidate in the American presidential race -2016 is assertive and selfconfident:

(9) I will be a Commander-in-Chief to get back in the business of creating a more peaceful world... Please clap! [28].

The call to applaud seems too self-assured, but the irony corresponds to American communicative values. On the one hand, the final appeal to the public may be considered as the evidence of the candidate's assertiveness and vision to the future, which is certain to be successful for him. On the other hand, the remark can be a way to hide embarrassment and discharge tension, which may have appeared in the end of the speech, when nobody reacts. So the ironic mask of a boastful person helps Jeb Bush to save the face and overcome the inconvenient pause. In this way, irony serves a double purpose: it optimizes the atmosphere of discourse and ensures the creation of a proper image of the speaker - charismatic and self-confident.

\section{Discussion}

These are but a few examples of contemporary political discourse, which can be viewed as bright examples of British and American political discourse. The whole material for the research counts around 100 speeches of 20 political and cultural figures from Great Britain and the USA within the period 2009-2019. The analysis of the speeches proves the hypothesis - irony has national and cultural peculiarities, which have an impact on the functions and mechanisms of ironic utterances and are closely connected with communicative values.

It should be noted, that the comparison of the speeches of British and American political and cultural figures reflected differences as well as common points. The study poses challenges for further discussion and opens vast perspectives for development.

\section{Conclusions}

The analyzed material proves that there are several common scenarios, which make the use of irony highly desirable in both English and American discourse. It conveys mockery and criticism, defend the speaker and protect his/her privacy, enhance intimacy between the speaker and the addressee/the audience, amuse and entertain.

The functions of irony and the frequency of its usage depend on the communicative values and the picture of the world, which form national mentality.

Communicative values are reflected in the language and influence the choice of strategies and expressive means. Irony is one of the instruments which is aimed at reaching the communicative intention of the author and performs a number of functions.

Irony has certain peculiarities in British and American political discourse. The research showed that in American political discourse in most cases it conveys criticism, attack, mockery, diminishes the opponent and portrays the speaker himself in a favourable way. British politicians use irony mainly for self-defense, to prevent criticism or close the unpleasant topic. Irony in the British discourse rather optimizes communication than raises contradictions.

Understanding irony used by a speaker requires background knowledge not only of national culture and traditions, but also about the speaker as a personality, including his education, social status, profession etc.

The effect of irony in political discourse depends on both parties - the author and the audience and is presupposed by a number of factors, such as cultural, national peculiarities, individual characteristics, background information, social level etc. Irony is a useful device, contributing to the success of communication, in case it is used appropriately and skillfully and interpreted correctly.

Analyzing humour and irony as a reflection of national character poses vast challenges for further research in the field of intercultural communication. The results of these studies can be used in teaching foreign languages and cultures, training interpreters and in the theory of discourse.

\section{References}

[1] Fox, K., Watching the English. The hidden rules of English behavior, Hodder and Stoughton, London, 2005.

[2] A. Soussa, A. Bazenga, L. Antunes, "Crosscultural humour: Humour that divides, humour that unites. An introduction", Journal of Linguistics and Intercultural 
Education, Vol. 2/2009 No.2, University of Madeira, Editura Aeternitas Alba Julia, 2009, pp. 9-11.

[3] Critchley, S., Ethics, Politics and racial Democracy: a History of a Disagreement, Culture Machine, vol. 4, 2002.

[4] M. Billig, "Critical Discourse Analysis and the Rhetoric of Critique", Critical Discourse Analysis: Theory and Interdisciplinarity, Palgrave Macmillan, 2007, pp. 3547.

[5] Fairclough, N., Language and power, Longman, 1996.

[6] A.M. Gouveia Carlos "Critical Discourse Analysis and the Development of the New Science", Critical Discourse Analysis: Theory and Interdisciplinarity, Palgrave Macmillan, 2007, pp. 47-63.

[7] P. Graham, "Critical Discourse Analysis and Evaluative Meaning: Interdisciplinarity as a Critical Turn “, Critical Discourse Analysis: Theory and Interdisciplinarity, Palgrave Macmillan, 2007, pp. 110130.

[8] J. Lemke, "Texts and Discourses in the Technologies of Social Organization", Critical Discourse Analysis: Theory and Interdisciplinarity, Palgrave Macmillan, 2007, pp.130-150.

[9] S. Scollon, "Political and Somatic Alignment: Habitus, Ideology and Social Practice", Critical Discourse Analysis: Theory and Interdisciplinarity, Palgrave Macmillan, 2007, pp. 167-199.

[10] Van Dijk, T. A., Society and discourse: how social contexts influence text and talk, Cambridge University Press, 2009.

[11] R. Wodak, "Critical Discourse Analysis", Discourse as Social Interaction, Vol. 2. - London: Sage Publications, 1997, pp. 259-284.

[12] Hutcheon, L. Irony's Edge. The Theory and Politics of Irony, New York: Routledge, 2005.

[13] F. Yus, "Attaching Feelings and Emotions to Propositions. Some Insights on Irony and Internet Communication", Russian Journal of Linguistics, 22 (1), pp. 94-107.

[14] Jandt, F., An introduction to intercultural communication. Identities in a global community, $4^{\text {th }}$ edition, Sage publications, 2004.

[15] Wierzbicka, A., English: Meaning and Culture, Oxford: Oxford University Press, 2006.

[16] Beebe, S.A., Beebe, S.J., Redmond, M.V., Interpersonal communication: relating to others. Pearson Education, Inc., 2007.
[17] Paxman, J, The English: A Portrait of a People. Penguin Books, 1999.

[18[ T. Larina, "Culture-Specific Communicative Styles as a Framework for Interpreting Linguistic and Cultural Idiosyncrasies", International Review of Pragmatics, 7 (2015), pp. 195-215.

[19[ DeVito, J.A. The Interpersonal Communication Book, 9th ed., Adison Wesley Longman, Inc., 2001.

[20] Brown, P., Levinson, S. D. Politeness: Some Universals in Language Usage, Cambridge: Cambridge University Press, 1987.

[21] A. Chudinov, O. Solopova, "Linguistic political prognostics: models and scenarios of future ", Procedia Social and Behavioral Sciences, Vol. 200, 2015, pp. 412417.

[22]https://www.hitc.com/en-gb/2017/11/13/borisjohnsons-4-best-quotes/.

[23] https://www.youtube.com/watch?v=Woy_rUyphOY TYouTube. Mayor of London Boris Johnson on David Letterman. 25.02.2014.

[24] https://www.youtube.com/watch?v=V1n7b8iTbqw YouTube. Boris Johnson's rugby scrum joke - BBC News, 6.10.2015.

[25] https://www.youtube.com/watch?v=ZdtzjLsaQSI YouTube. 2013 Tory party conference. PM David Cameron keynote speech, 02.10.2013.

[26] https://www.youtube.com/watch?v=LZZzw1QTy1w YouTube. Obama's best 2016 jokes at the White House Correspondents' Dinner, 25.04.2015.

[27] https://www.youtube.com/watch?v=yGgxr4Sxoas YouTube. Al Smith dinner, 20.10.2016.

[28] https://www.youtube.com/watch?v=DdCYMvaUcrA YouTube. Jeb Bush: "Please Clap...", 3.02.2016.

\section{Acknowledgements}

I express my gratitude to the organizing committee of Ireland International Conference on Education (IICE-2019) for giving an opportunity to present the report and discuss the suggested hypothesis with colleagues. 